\title{
Osteometric Parameters of Femur in Telangana Region
}

\author{
*Dr Ashish Kamdi ${ }^{1}$, Dr Gayatri ${ }^{2}$, Dr Anil R. Sherke ${ }^{3}$, Dr M. Krishnaiah ${ }^{4}$, \\ Mr K.Chaitanya 5 . \\ 1,2,3,4,5 Department of Anatomy, Kamineni Institute Of Medical Sciences, Narketpally.
}

\begin{abstract}
:
Introduction: The femur is longest and strongest bone in the body. Sex determination from unidentified human skeletal elements is a challenge for forensic investigators and anthropologists.

Aim of the Study: To correlate different osteometric parameters of femur for anthropological and forensic practise.

Materials \& Method: Study was conducted with 40 femora (right 28 and left 12) of unknown sex from the Department of Anatomy, Kamineni Institute of Medical Sciences, Narketpally. Femora were subjected for measuring length, anterio-posterior diameter of shaft at upper, middle and lower segment using osteometric board and vernier calliper.
\end{abstract}

Results: Mean length of femur was $43.26 \mathrm{~cm}$ and mean antero-posterior diameter of shaft at upper segment was $24.67 \mathrm{~mm}$, middle segment was $25.1 \mathrm{~mm}$ and lower segment was $25.77 \mathrm{~mm}$.

Conclusion: The knowledge of morphometric values is helpful to anthropological and forensic practice.

Key words: Sexual dimorphism, Anthropological practise, Osteometric measurments.

\section{Introduction}

Determination of sex from unidentified human skeletal remains is a challenge for anthropologists and forensic investigators. Skeleton plays a significant role in various sciences like medicine, forensic sciences, anthropology. Estimation of sex, age, race, stature by skeleton and the presence of disease is discovered by Krogman and Iscan ${ }^{1}$. They stated that record of organic evolution is largely written by the hard parts of the body recognizable even after many years after death. Skull and pelvis ${ }^{2}$ are widely used for sex identification. Physical anthropologists and forensic pathologists have given utmost importance to the methods of stature estimation from long bones. The bones of the lower extremity namely the femur and tibia have yielded consistent and good results. Femur is the largest and heaviest bone of the human skeleton ${ }^{3}$. In the present study we are taking the femur either individually or in combination has been subjected to statistical and morphological analysis. Examination and statistical analysis of femoral anthropometry among different populations reveals a great amount of variation due to the fact that the femoral anthropometry measurements from different countries are like to be affected by racial variations in diet, heredity. Difference in the measurements between male and female could be attributed to difference in the duration of ossification of different centers in a developing femur of male and female ${ }^{4}$. Osteometric measurements are used for sex identification. The purpose of this research study is to explore the osteometric difference between male and female femurs of Telangana region and compare with available literature. Strecker et $\mathrm{al}^{5}$ stated that mean values of lengths of right and left femora were found to be similar, although the left femur generally showed larger values than right, they were not significantly greater.Parsons ${ }^{6}$ proposed that there was no significant bilateral difference found in bones, he reported that males has bigger neck shaft angles than females through his study and statement in population, in another study of same author studied on sex determination of human femur by using univariate or multivariate discriminate analysis. Paersons and bell ${ }^{7}$ stated that there was no significant statistical bilateral difference found in bones. Lealavathy et al ${ }^{8}$ stated that maximum length of femur was found to be the best parameter in sex determination of the femora. The knowledge of morphometric values is helpful to anthropological and forensic practice.

\section{Material \& Method}

40 human femora (left 12 and right 28) from department of anatomy, Kamineni Institute of Medical Sciences, Narketpally were used for the study. Femora of unknown sex were used for this study. Vernier calliper and osteometric board were used to carry out readings. All readings were taken 3 times by same person to prevent inter-observer error. Maximum length and anterio-posterior diameters of upper, middle and lower segments of shaft of femur were measured. Samples with pathological changes were excluded.

Length of femur - Femur fixation to osteometric board is done in such a way that both epicondyles touch vertical wall; dorsal side of femur in upward direction. Highest point of head should touch the movable piece of 
osteometric board. Maximum length is measured between highest point of the head and deepest point on medial condyle.

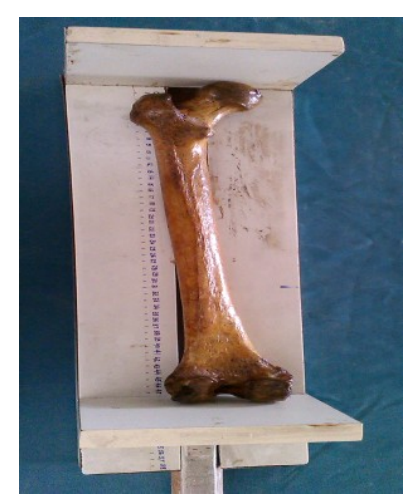

Anterio-posterior diameter of shaft using vernier calliper -

Upper segment - Anterio-posterior diameter of the shaft is measured at right angle to the transverse diameter of the shaft.

Middle segment - Anterio-posterior diameter of the shaft is measured at mid shaft region showing maximum elevation of the linea aspera.

Lower segment - Anterio-posterior diameter of the shaft is measured approximately 4 cms above cartilaginous margin of the condyles.

Mean length of femur $=43.26 \mathrm{~cm}$

\section{Results}

Left was $-43.28 \mathrm{~cm}$

Right was $-43.19 \mathrm{~cm}$

Maximum length of femur $=48.2 \mathrm{~cm}$

Minimum length of femur $=37.8 \mathrm{~cm}$

Mean antero-posterior diameter of the shaft at upper segment $-24.67 \mathrm{~mm}$

Mean antero-posterior diameter of the shaft at upper segment on right side $-24.78 \mathrm{~mm}$

Mean antero-posterior diameter of the shaft at upper segment on left side $-24.42 \mathrm{~mm}$

Mean antero-posterior diameter of the shaft at middle segment $-25.1 \mathrm{~mm}$

Mean antero-posterior diameter of the shaft at middle segment on right side $-25.14 \mathrm{~mm}$

Mean antero-posterior diameter of the shaft at middle segment on left side $-25.06 \mathrm{~mm}$

Mean antero-posterior diameter of the shaft at lower segment $-25.77 \mathrm{~mm}$

Mean antero-posterior diameter of the shaft at lower segment on right side $-27.75 \mathrm{~mm}$

Mean antero-posterior diameter of the shaft at lower segment on left side $-25.83 \mathrm{~mm}$

No significant difference was found between right and left side.

\section{Discussion}

Male skeleton is considered to be longer and more robust than the average female, the magnitude differs from population to population. This difference can be attributed to genetic factors, environmental factors affecting growth and development like nutrition, physical activity. The measurement of long bones carry additional advantage because of its tubular nature and it can be better preserved than short bones. The femur is the longest \& strongest bone in the human body. Its length is associated with a striding gait, its strength with the weight and muscular forces it is required to withstand. Femur measures about $45 \mathrm{~cm}$ (18 inches) long in an average man which means, approximately one-fourth of the height of the individual. The femur presents upper and lower ends, and intervening shaft. The shaft is more or less cylindrical. It is narrowest in the middle, and is more expanded inferiorly than superiorly. It is convex forwards and is directed obliquely downwards and medially, because the upper ends of the femora are separated by the width of the pelvis, and their lower ends are together. In the middle one-third- the shaft has three borders, medial, lateral and posterior and three surfaces, anterior, medial and lateral. The medial and lateral borders are ill-defined and rounded, but the posterior border is in the form of a broad rounded ridge, called the linea aspera. The linea aspera has distinct medial and lateral lips. In the upper one third of the shaft- the two lips of the linea aspera diverge to enclose the additional posterior surface. Thus it has four borders, medial, lateral, spiral line and lateral lip of gluteal tuberosity and four surfaces anterior, posterior, medial and lateral. The gluteal tuberosity is the broad rough ridge on the lateral part of the posterior surface. In the lower third of the shaft- the two lips of the linea aspera diverge as supracondylar lines to enclose an additional, popliteal surface. Thus this part of the shaft has four borders medial, lateral, 
medial supracondylar line and lateral supracondylar line and four surfaces, anterior, medial, lateral and popliteal.

The maximum length of the femur varies from a minimum of $371 \mathrm{~mm}$ to maximum of $512 \mathrm{~mm}$ with a mean value of $436.3 \mathrm{~mm}$. When this is compared to the range of the known sex, 29 femora out 40 could be identified as belonging to male and 11 to female. Maximum length of femur has been reported earlier by Leelavathy N, et al. $2000^{9}$. Comparisons were drawn separately for male left and right femora as well as for female left and right femora, because individuals tend to favour one limb over other. It also has been observed that the female femur is shorter than male and in male the left longer than right and vice versa in female. Maximum length of femur was the best parameter for sexing the unknown femora by Leelavathy et al. $2000^{10}$. Discriminant analysis confirmed that the male femur is usually larger than the female femur (Alan M. W Porter $1994^{11}$ ) sex differences in long bones is that typically male bones are longer and more massive than typically female bones $\left(\operatorname{krogman}^{12}\right)$.

Anteroposterior diameter of femoral shaft, in the present study we had taken measurements of femoral shaft at three different sites, Upper-just below the lesser trochanter, Middle - approximately at the middle of shaft, ie. Highest elevation of linea aspera. It measures the distance between anterior and posterior surfaces of the bone. Lower - approximately $4 \mathrm{~cm}$ above the cartilaginous margin of condyles taken in mid sagittal plane. Upper anteroposterior diameter of femur ranges from minimum of $21 \mathrm{~mm}$ to maximum of $31 \mathrm{~mm}$ with a mean value of $24.67 \mathrm{~mm}$. Middle anteroposterior diameter of femur varies from minimum of $21 \mathrm{~mm}$ to maximum of $31 \mathrm{~mm}$ with a mean value of $25.14 \mathrm{~mm}$. Lower anteroposterior diameter of femur ranges from minimum of 20 $\mathrm{mm}$ to maximum of $33 \mathrm{~mm}$ with a mean value of $25.81 \mathrm{~mm}$. When this is compared to the range of known sex 28 out of 40 femora could be identified as belonging to male and 12 to female by using middle APD. Anteroposterior diameter of femoral shaft has been reported earlier (Rumapurkait $1996^{13}$ ). Studies by Iscan ${ }^{14}$ reveal that all dimensions of femur were larger in males than in females, but determination of sex of an individual from a single femur was a more difficult task (Taner Ziylan $2002^{15}$ ). The shaft of femur is so shaped that it varies at mid-level and at subtrochanteric level. Hence several transverse and sagital diameters are useful $\left(\operatorname{Krogman}^{1}\right)$.

\section{Summary And Conslusion}

40 dry human femora of unknown sex were collected from department of anatomy, Kamineni Institute of Medical Sciences, Narketpally . By eliminating pathologically misfit femora, 40 femora in good condition were selected. Each femur was carefully measured for the parameters which are already described in materials and methods. The measurements were statistically analyzed and tabulated.

For each femur accurate measurements are taken for 2 parameters namely:

1. Maximum length of femur

2. AP diameter of shaft - Upper, Middle, Lower

The measurements were compared to the values available in reference material. Every parameters is independent of others and contribute certain percentage of certainty to decide the sex of unknown femur. The knowledge of morphometric values is helpful to anthropological and forensic practice.

\section{Acknowledgments}

The authors acknowledge great help received from the authors / editors / publishers of all those articles, journals and books from where the literature for this article has been reviewed and discussed. We also acknowledge great help received from the scholars whose articles cited and included in references of this manuscript.

\section{References}

[1]. Krogman, W. M. and Iscan, M. Y. Human Skeleton in Forensic Medicine. 2nd Edition, Charles C. Thomas, Springfield, 1986.

[2]. Asala . S.A. et al 2004 Discriminant function sexing of fragmentary femur of South African blacks, vol 145, issue 1. p. 25-29

[3]. Bannister Lawrence. H 1995 Gray's Text Book of Anatomy, 38th Edition P. 678-684

[4]. Taner Ziylan2002 An Analysis of Anatolian Human femur Anthropomet6ry, Turkey Journal of Medical Sciences, Vol - 32, P. 2312

[5]. Strecker W, Keppler P, Gebhard F, Kinzl L. Length and torsion of the lower limb. J Bone Joint Surg Br. 1997; 79(6):1019-23.

[6]. Parsons, F.G. The character of the English thigh bone. Journal of Anatomy and physiology 1914; 48: 238-267.

[7]. Pearson K and Bell J. A study of long bones of the English Skelton Part-I femur, in the influence of race side and sex. Cambridge University Press, London, 1919; 128-130pp.

[8]. Leelavathy N, Rajangam s, Janakiram S, Thomas JM. Sexing of the femora. Indian journal of anatomical. Society of india.2000; 49(1):17-20.

[9]. Leelavathy N, Rajangam s, Janakiram S, Thomas JM. Sexing of the femora. Indian journal of anatomical. Society of india.2000; 49(1):17-20.

[10]. Leelavathy N, Rajangam s, Janakiram S, Thomas JM. Sexing of the femora. Indian journal of anatomical. Society of india.2000; 49(1):17-20.

[11]. Alan M.W.Porter1995Analysisof measurement from adult femora of British population.

[12]. Krogman, W. M. and Iscan, M. Y. Human Skeleton in Forensic Medicine. 2nd Edition, Charles C. Thomas, Springfield, 1986.

[13]. Ruma Purkait2004 A study of sexual variation in Indian femur,Vol 146, issue,p:25-33.

[14]. Yasar Iscan M, Ding Shihai. Sexual dimorphism in the Chinese femur. Forensic science international. $1995 ; 74 ; 79-87$.

[15]. Taner Ziylan2002 An Analysis of Anatolian Human femur Anthropomet6ry, Turkey Journal of Medical Sciences, Vol 32, P.231235. 